\title{
Sekolah Dolanan Tradisional: Sebagai Tempat Pengembalian Eksistensi Permainan Tradisional di Kampung Tambak Lorok Semarang
}

Traditional Dolanan School : as a Place to Restore The Existence of Traditional Games in The Village of Tambak Lorok Semarang

\author{
Rexza Berliyana $^{1}$, Rachelina Nur Ilyasaf $^{2}$, Sari Ayu wulandari ${ }^{3}$ \\ ${ }^{1,2,3}$ Fakultas Teknik Universitas Dian Nuswantoro \\ e-mail: ${ }^{1}$ rexzaberliyana12@ gmail.com, ${ }^{2}$ ilyasafrachel@gmail.com, \\ ${ }^{3}$ sari.wulandari@dsn.dinus.ac.id
}

\begin{abstract}
Abstrak
Indonesia adalah negara dengan kekayaan yang sangat ruah melimpah. Dimulai dari sumber daya alam, tanah yang subur dan kekayaan budaya. Berdasarkan data sensus penduduk pada tahun 2010 menyebutkan bahwa ada 1.331 suku dan 652 bahasa daerah yang berbeda. Tidak hanya terletak dari kekayaan bahasa daerah, indonesia juga memiliki kekayaan pada budayanya. Salah satu dari kekayaan budaya di Indonesia adalah permainan tradisional. Permainan tradisional adalah permainan yang telah diturunkan dari satu generasi ke generasi berikutnya dengan permainan tersebut mengandung nilai baik, positif, bernilai dan diinginkan [2]. Permasalahan terhadap mulai ditinggalkannya permainan tradisional dikalangan anak-anak ini terjadi di salah satu wilayah di kota Semarang. Permasalahan ini terjadi di Kampung Tambak Lorok. Kampung Tambak Lorok adalah salah satu wilayah di kota semarang yang sebagian besar penduduknya bekerja sebagai nelayan. Kurangnya minat anak-anak dalam bermain permainan tradisional membuat eksistensi permainan tradisional dikalangan anak-anak mulai memudar dan jarang dimainkan. Dari permasalahan tersebut maka perlu adanya sebuah solusi yaitu dengan diadakannya sebuah sekolah sabtu untuk mengenalkan kembali kepada anak-anak tentang permainan tradisional yang eksistensinya mulai dilupakan oleh kalangan anak-anak Indonesia khususnya anak-anak Tambak Lorok Kota Semarang.
\end{abstract}

Kata Kunci: Permainan tradisional, Eksistensi, dan Tambak Lorok

\begin{abstract}
Indonesia is a country with abundant wealth. Starting from natural resources, fertile land and cultural wealth. Based on population census data in 2010 there were 1,331 tribes and 652 different regional languages. Not only lies in the wealth of local languages, Indonesia also has a wealth of culture. One of the riches of culture in Indonesia is the traditional game. Traditional games are games that have been passed down from one generation to the next with these games containing good value, positive, valuable and desirable [2]. The problem with the abandonment of traditional games among children has occurred in one area in the city of Semarang. This problem occurs in Kampung Tambak Lorok. Kampung Tambak Lorok is one of the areas in Semarang city where most of the residents work as fishermen. Lack of children's interest in playing traditional games makes the existence of traditional games among children begin to fade and are rarely played. From these problems, it is necessary to have a solution that is by holding a Saturday school to introduce children back to traditional games whose existence has begun to be forgotten by Indonesian children, especially children from Tambak Lorok, Semarang City.
\end{abstract}

Keywords : Traditional game, Existence, and Tambak Lorok 


\section{PENDAHULUAN}

Indonesia adalah negara dengan kekayaan yang sangat ruah melimpah. Dimulai dari sumber daya alam, tanah yang subur, dan kekayaan budaya. Berdasarkan data sensus penduduk pada tahun 2010 menyebutkan bahwa ada 1.331 suku dan 652 bahasa daerah yang berbeda. Tidak hanya terletak dari kekayaan bahasa daerah, indonesia juga memiliki kekayaan pada budayanya. Salah satu dari kekayaan budaya di Indonesia adalah permainan tradisional. Permainan adalah segala sesuatu yang bersifat gerakan. Permainan merupakan sebuah aktivitas rekreasi dengan tujuan bersenang-senag,mengisi waktu luang, atau berolahraga ringan [1]. permainan tradisional adalah permainan yang telah diturunkan dari satu generasi ke generasi berikutnya dengan permainan tersebut mengandung nilai baik, positif, bernilai dan diinginkan [2]. Dalam permainan tradisional terkandung nilai-nilai pendidikan yang secara tidak langsung terlihat nyata, tetapi terlindungi dalam sebuah lambang dan nilai-nilai tersebut berdimensi banyak seperti rasa kebersamaan, kejujuran, kedisiplinan, sopan santun, gotong royong dan aspek-aspek kepribadian lainnya [3]. Bangsa Indonesia memiliki permainan anak yang kaya akan nilai dan berdasarkan penelitian permainan anak tradisional dapat menstimulasi tumbuh kembang anak, bahkan dapat digunakan sebagai sarana edukasi pada anak [4].

Seiring dengan berkembangnya zaman permainan tradisional mulai ditinggalkan dan semakin kurang diminati, khususnya pada lingkup anak-anak. Hal ini dikarenakan anak yang tinggal di daerah kota, apalagi kota-kota besar cenderung menyukai permainan elektronik seperti video game, playstation, game online, dan berbagai permainan yang tersedia dikomputer, handphone, laptop, dan permainan modern lainnya [6]. Nilai-nilai yang ada pada permainan tradisional perlu disadari oleh kalangan-kalangan tertentu bahwa pada era globalisasi ini nilai-nilai didaktis dalam permainan tradisional anak perlu digali kembali, karena baru ini (modern) dianggap semakin menjauhkan anak dari nilai didaktis seperti yang ada pada permainan tradisional anak [7]. Keengganan untuk memainkan dan mengenal budaya lokal seperti permainan tradisional merupakan sebuah ancaman bagi generasi bangsa dalam proses pewarisan budaya lokal permainan tradisional.

Permasalahan terhadap mulai ditinggalkannya permainan tradisional dikalangan anak-anak ini terjadi di salah satu wilayah di kota Semarang. Permasalahan ini terjadi di Kampung Tambak Lorok. Kampung Tambak Lorok adalah salah satu wilayah di kota semarang yang sebagian besar penduduknya bekerja sebagai nelayan. Kurangnya minat anak-anak dalam bermain permainan tradisional membuat eksistensi permainan tradisional dikalangan anak-anak mulai memudar dan jarang dimainkan. Sehingga, kelak generasi selanjutnya bangsa Indonesia tidak dapat mengenal atau mengetahui tentang warisan budaya bangsa Indonesia khususnya permainan tradisional. Dari permasalahan tersebut maka perlu adanya sebuah solusi yaitu dengan diadakannya sebuah sekolah sabtu untuk mengenalkan kembali kepada anak-anak tentang permainan tradisional yang eksistensinya mulai dilupakan oleh kalangan anak-anak Indonesia khususnya anak-anak Tambak Lorok Kota Semarang. 


\section{METODE PELAKSANAAN}

Metode yang digunakan dalam pelaksanaan kegiatan ini menjelaskan langkahlangkah yang digunakan untuk mengatasi permasalahan yang akan dipecahkan. Dalam pelaksanaan ini terdapat 6 metode yang digunakan yaitu survei lokasi kegiatan, sosialisasi masyarakat sasaran dan penyuluhan, pelaksanaan kegiatan (pengabdian), monitoring dan evaluasi kegiatan, keberlanjutan progam dan pasca kegiatan.

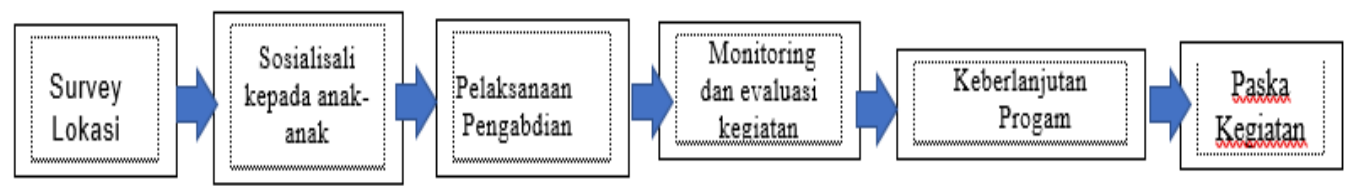

Gambar 1. Alur diagram metode pelaksanaan

a) Survei lokasi Kegiatan

Kegiatan awal pelaksanaan progam ini adalah melakukan survei lokasi pada tempat yang akan dilakukan pengabdian masyarakat yaitu kampung tambak lorok kota semarang di komunitas asa edu. Kegiatan ini meliputi peninjauan tempat dan observasi masyarakat.

b) Sosialisasi dan Penyuluhan terhadap masyarakat sasaran

Pada kegiatan ini dilakukannya sosialisasi kepada komunitas asa edu tentang progam pengabdian yang akan kami lakukan, dilanjutkan dengan penyuluhan kepada anak-anak Tambak Lorok yang bekerja sama dengan komunitas asa edu tentang Sedot (Sekolah Sabtu Dolanan Tradisional) dan permainan tradisional.

c) Pelaksanaan Kegiatan (Pengabdian)

Kegiatan ini merupakan pelaksanaan pengabdian kepada anak-anak di tambak lorok yang bekerja sama dengan komunitas asa edu. Sedot (Sekolah Sabtu Dolanan Tradisional) dilaksanakan setiap hari sabtu. Pada pengabdian ini kami memberikan penyuluhan tentang permainan tradisional dan pelatihan membuat mainan tradisional. Pelatihan yang kami lakukan adalah membuat layanglayang, alat lompat tali dari karet, menggambar permainan tradisional indonesia.

d) Monitoring dan evaluasi kegiatan

Tujuan dari kegiatan ini adalah untuk mengetahui kegiatan atau pengabdian yang telah dilakukan sudah terlaksana dengan baik dan benar.

e) Keberlanjutan Progam

Pada tahap ini akan dilaksanakan pembentukan tim keberlanjutan progam pengabdian. Hal ini dilakukan guna menjalin kemitraan untuk kegiatan 
kedepannya serta keberlanjutan progam sedot tetap berjalan meskipun progam dari PKM-M telah selesai.

f) Pasca Kegiatan

Tahap akhir dari progam pengabdian masyarakat ini adalah evaluasi program yaitu dengan melakukan survey pelaksanaan program, pembandingan tingkat penguasaan materi anak sebelum dan sesudah pengabdian, dan pembuatan laporan dan luaran program. Survey pelaksanaan dilakukan dengan menggunakan metode survey tertulis dan wawancara. Survey tertulis dilakukan untuk komunitas Esa Edu untuk mengetahui tentang karakter pembelajaran dan tingkat pemahaman SOP dari tiap divisi (nilai rata-rata sebelum PKMM = 75 dan setelah PKMM = 98), sedangkan survey wawancara dilakukan untuk mengetahui minat dan antusiasme masyarakat, baik dari sisi anak-anaknya maupun dari sisi ibu-ibu yang mengantarkan anaknya. Hasil dari wawancara tersebut adalah, masyarakat sasaran mempunyai minat dan antusiasme yang tinggi terhadap program pengabdian yang dilaksanakan, hal ini dapat dilihat dari antusiasme mereka dalam menghadiri dan turut serta dalam setiap kegiatan sedot.

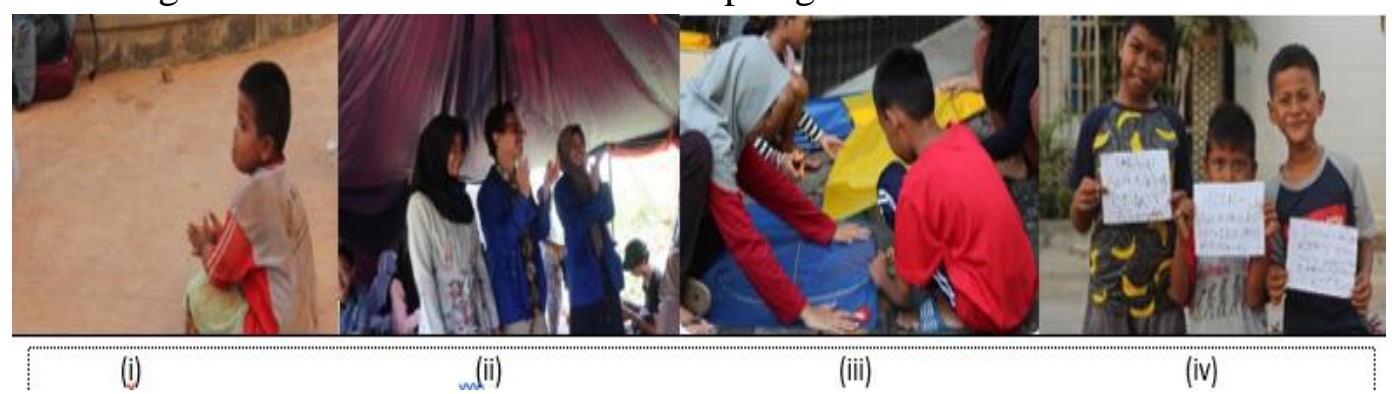

Gambar 2. (i) survei lokasi, (ii) sosialisasi dan penyuluhan, (iii) pelaksanaan kegiatan, dan (iv) paska kegiatan

\section{HASIL DAN PEMBAHASAN}

Berdasarkan kegiatan pengabdian yang telah dilakukan maka Pelaksanaan progam kreativitas mahasiswa dalam bidang pengabdian masyarakat mengacu pada keberhasilan jangka pendek dan keberhasilan jangka panjang. Keberhasilan progam dapat dilihat dari keberhasilan luaran yang telah tercapai. Progam Sedot (Sekolah Sabtu Dolanan Tradisional) dilaksanakan di Kampung Tambak Lorok Kota Semarang yang bekerja sama dengan komunitas Asa Edu telah berjalan dengan baik. Hal ini dikarenakan semua kegiatan yang dilakukan sesuai dengan plan action yang terjadwal. Hasil yang telah dicapai dari progam ini adalah diadakannya Penyuluhan, Pelatihan dan Bermain Permainan tradisional yang dilakukan setiap seminggu sekali yaitu pada hari sabtu. Dari pengabdian yang dilakukan anak-anak Tambak Lorok Kota Semarang telah mengenal kembali permainan tradisional yang mulai hilang keberadaannya disekitar masyarakat Indonesia khususnya anak-anak. Hal ini terbukti anak-anak tambak lorok kota 
semarang dapat menggambar nama permainan tradisional yang telah kami ajarkan kepada mereka, Tidak hanya itu anak-anak yang sebelumnya belum bisa bermain permainan tradisional seperti lompat tali, egrang dan bola bekel kini mereka bisa memainkannya.
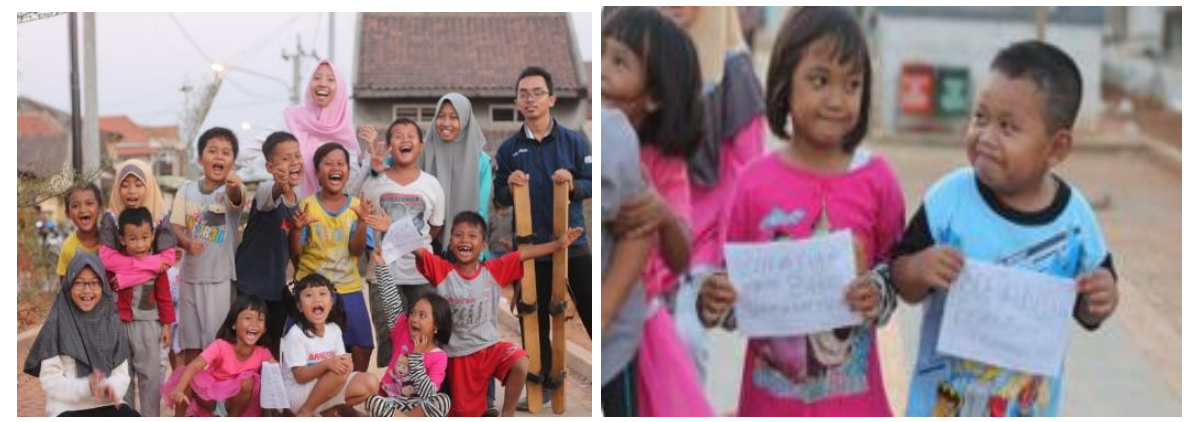

Gambar 3. Pengabdain bersama anak tambak lorok (i), pendapat anak tambak lorok tentang pegabdian yang dilakukan (ii)

Dari kegiatan penyuluhan dan pengajaran yang dilakukan, anak- anak Tambak Lorok Kota Semarang mulai memainkan kembali permainan tradisional seperti lompat tali, balap karung, bola bekel layangan dan permainan tradisional lainnya. Mitra dari kegiatan Pengabdian ini (komunitas asa edu) berpendapat bahwa kegiatan ini sangat bermanfaat bagi anak-anak dikampung tambak lorok Kota Semarang dalam pelestarian permainan tradisional, memainkan kembali permainan tradisional dan pengembalian jiwa cinta anak-anak indonesia khususnya anak-anak tambak lorok Kota Semarang dalam mengenal budaya lokal khususnya permainan tradisional.

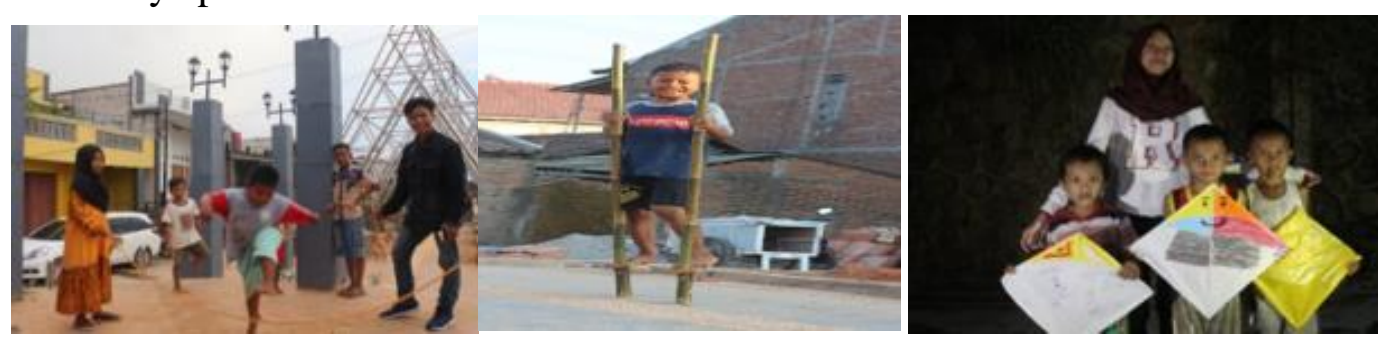

Gambar 4. Kegiatan pengabdian yang telah dilakukan

lompat tali (i) Egrang (ii), dan membuat laying-layang oleh anak-anak (iii)

\section{KESIMPULAN}

Permainan rakyat atau sering disebut dengan nama permainan tradisional adalah sebuah permainan yang telah diwariskan nenek moyang bangsa Indonesia dari zaman dahulu hingga sekarang, didalam permainan ini terkandung nilai-nilai kehidupan seperti kerjasama, gotong royong, kejujuran, dan rasa empati antar sesame teman yang memiliki dampak positif kepada anak-anak yang memainkannya, seiring dengan perkembangan zaman dan arus globalisasi yang masuk di Indonesia membuat eksistensi terhadap permainan tradisional telah tergeser dari kehidupan anak-anak Indonesia dan digantikan dengan permainan 
modern atau sering disebut dengan game online. Oleh karena itu dengan adanya kegiatan Sedot ini dapat mengembalikan eksistensi permainan tradisional dan rasa cinta terhadap budaya Indonesia dikalangan anak-anak Indonesia, khususnya anak-anak Kampung Tambak Lorok Kota semarang. Sehingga, tetap adanya regenerasi pewarisan budaya dan permainan tradisional di Indonesia serta anakanak dapat memainkannya kembali, tanpa takut permainan tersebut tergerus oleh perkembangan zaman.

\section{SARAN}

Saran penulis untuk kegiatan pengabdian selanjutnya adalah ditingkatkan jumlah peserta pengabdian dan waktu pendampingan dalam melaksanakan pengabdian masyarakat.

\section{UCAPAN TERIMAKASIH}

Penulis mengucapkan terimakasih kepada derektorat penelitian dan pengabdian kepada masyarakat, Kementrian Riset, Teknologi, dan Pendidikan Tinggi pada progam kreativitas mahasiswa tahun 2019, dosen pembimbing dalam penulisan artikel ilmiah, ketua jurusan progam studi, wakil rektor bidang kemahasiswaan yang telah memberikan dukungan, dan beberapa pihak yang tidak dapat kami sebutkan satu persatu.

\section{DAFTAR PUSTAKA}

[1] D. Hidayat, 2013, Permainan Tradisional Dan Kearifan Lokal Kampung Dukuh Garut Selatan Jawa Barat, vol. 05, no. 02, pp. 1057-1070.

[2] M. Bhisop, Julia C dan Curtis, Permainan Anak-Anak Zaman Sekarang di Sekolah Dasar. Jakarta: PT Grasindo.

[3] F. M. Halim, 2014, Interior Museum Permainan Anak-Anak Tradisional Jawa di Surabaya, vol. 2, no. 2, pp. 826-833.

[4] H. Nur, 2013, Membangun Karakter Anak Melalui Permainan Anak Tradisional, vol. 3, pp. 87-94.

[5] D. Fauziah, 2015, Nilai Edukatif Dalam Permainan Tradisional Anak, Diakses dari http://www.metrosiantar.com/2015/21/191467/nilai-edukatifdalampermainan-tradisional-anak/.

[6] S. Dharmamulya, Permainan Tradisional Jawa. Yogyakarta: Kepel Press. 